\title{
Cuerpo y performatividad: una revisión crítica desde la perspectiva del psicoanálisis
}

\author{
Body and Performativity: a critical review from the point of \\ view of psychoanalysis
}

ANA CECILIA GONZÁLEZ*

\begin{abstract}
Resumen: Teniendo en cuenta el carácter de paradigma hegemónico que la teoría de la performatividad del género de Judith Butler ha adquirido en el ámbito del feminismo académico y las ciencias sociales en general, resulta necesario efectuar una revisión crítica de los alcances y límites de dicho paradigma. En este artículo me propongo efectuarla desde un ángulo particular, que es el de la tensión abierta con el psicoanálisis -en particular los trabajos de Freud y Lacan-, que configura una constante en la obra de la teórica queer. Aunque esta relación es bien conocida, en general se la ha reducido a la controversia «diferencia sexual versus género». Con el fin de reactualizar el debate propongo poner
\end{abstract}

\begin{abstract}
Considering the hegemonic status of Judith Butler's theory on the performativity of gender in both feminist theory and social sciences, a critical review of its strengths and limits has become necessary. In this paper I face this task from a particular angle, that of the tension with psychoanalysis -specially the works by Freud and Lacan- which appears as a constant in the work of the queer theorist. Although this tension is well known, it has generally been identified to the controversy «sexual difference versus gender». In order to bring up to date the discussion, I propose to focus on the various notions of body that Butler elaborates in the consecutive moments of her
\end{abstract}

Fecha de recepción: 03/06/2014. Fecha de aceptación: 19/11/2014.

* Este trabajo fue redactado como doctoranda y becaria FI del Departamento de Filosofía de la Universidad Autónoma de Barcelona, e integrante del grupo «Cuerpo y textualidad». Actualmente la autora ha obtenido el doctorado y se desempeña como investigadora y docente de la cátedra «Ética y Derechos Humanos-I» de la Facultad de Psicología de la Universidad de Buenos Aires. Líneas de investigación actuales: tratamiento científico del cuerpo, incidencias subjetivas, biopolíticas y bioéticas de las tecnologías de reproducción asistida y nuevas configuraciones familiares. Publicaciones recientes: Ana Cecilia González (2014): 1) «La extimidad amenazada» Journal Ética y Cine, V(4) 2, pp. 23-29; 2) Ana Cecilia González y Begonya Sáez Tajafuerce (2014): «El cuerpo en/del arte. La experiencia de lo éxtimo». Res Publica. Revista de Filosofía Política - Universidad de Murcia/ Universidad Complutense de Madrid. Vol 17- 2; 3) Ana Cecilia González (2013): «El registro autobiográfico como paradigma del pensamiento feminista». Forma Revista d' Estudis Comparatius d'Art, Literatura i Pensament. Vol. 08, pp. 81-96; 4) Ana Cecilia González y Begonya Sáez Tajafuerce (2013) «El cuerpo en la diferencia sexual», en Cevasco, R., Copjec J., y Zupančič, A., Ser-para-el-sexo, R. Diálogo entre psicoanálisis y filosofía. Barcelona, Editorial S\&P, pp. 9-21; 5) Ana Cecilia González (2014): «Cuerpo, desublimación y retorno de lo real. Entre psicoanálisis y teoría del arte», en Janeiro. F, Jornet, A, Saccone, D. y Sancho, S (eds): Facing humanities. Current perspectives from Young researchers. Barcelona: Universitat Pompeu Fabra - Forma Revista d'Estudis Comparatius d'Art, Literatura i Pensament pp.139-14. Correo electrónico: anaceciliagonzalezr@gmail.com 
el foco sobre las diversas nociones de cuerpo que ella elabora en los sucesivos momentos de su producción, y el modo en que esto se articula con el debate abierto con el psicoanálisis.

Palabras clave: Judith Butler; cuerpo-texto; cuerpo-abyecto; psicoanálisis lacaniano. production, and the way they are articulated to the open debate with lacanian psychoanalysis.

Key Words: Judith Butler; body-text; bodyabjection; lacanian psychoanalysis.

\section{Introducción}

Ha pasado casi un cuarto de siglo desde la primera edición de Gender Trouble (1990), el libro de Judith Butler que significó una verdadera revolución en el campo de las filosofía feminista contemporánea. Teniendo en cuenta el carácter de paradigma hegemónico que su teoría de la performatividad del género ha adquirido en el ámbito del feminismo académico, y también en el de las ciencias sociales en general, resulta necesario efectuar una revisión crítica de los alcances y límites de dicho paradigma, teniendo en cuenta asimismo los giros que la propia Butler ha ido efectuando en su recorrido, a menudo pasados por alto en aplicaciones apresuradas. En este artículo me propongo efectuar una lectura desde un ángulo particular, que es el de la tensión abierta con el psicoanálisis -en particular los trabajos de Freud y Lacan-, que configura una constante en la obra de la teórica queer. Aunque esta relación es bien conocida, en general se la ha reducido a la controversia «diferencia sexual versus género», pasando por alto otros aspectos relevantes de la relación, como ser la «importación»-en el sentido de tomar un concepto de otra teoría y aplicarlo al propio campo de estudio- de determinados conceptos psicoanalíticos y la función que cumplen en la teoría de Butler, lo cual procuraré poner de manifiesto. Con el fin de reactualizar el debate, me interesa poner el foco sobre las diversas nociones de cuerpo $^{1}$ que ella elabora en los sucesivos momentos de su producción, y el modo en que esto se articula con el debate abierto con el psicoanálisis. Desde esta perspectiva, voy a desarrollar cuatro puntos. Comenzaré por situar los ejes genealógicos y estratégicos de la teoría de la performatividad, de modo de explicitar la función del psicoanálisis en la empresa teórica butleriana. Luego expondré los postulados principales de la primera formulación de la teoría de la performatividad, atendiendo especialmente al estatuto textual que Butler confiere al cuerpo, y las críticas que ha recibido de parte de determinadas teóricas que defienden la teoría de Lacan. A continuación, haré foco en el modo en que la teórica norteamericana responde a las críticas elaborando una segunda formulación de la teoría de la performatividad, en la que propone otras nociones de cuerpo. Por último, y como la aportación de mayor especificidad de este trabajo, presentaré la crítica que puede hacerse desde el psicoanálisis a lógica identitaria que atraviesa la teoría del performatividad, dejando planteado un interrogante sobre la noción de vulnerabilidad, que es el punto de arribo de la reflexión butleriana en torno al estatuto del cuerpo.

1 Este trabajo recoge parte de lo elaborado en mi tesis doctoral, en la que he desarrollado los debates contemporáneos acerca de los usos y estatutos del cuerpo según tres imágenes metafóricas fundamentales, el cuerpo-texto, el cuerpo-abyecto, el cuerpo-frontera, y desde la doble perspectiva del psicoanálisis y la filosofía contemporánea. El núcleo está condensado en un artículo, cf. Ana Cecilia González (2014): «Trois images du corps: problematiques contemporaines entre philosophie et psychanalyse», en Llevadot, L.; Riba, J.; Vermeren, P.: Barcelone pense-t-elle en français? Paris: L'Harmattan. 


\section{La performatividad: genealogía y ejes estratégicos}

La performatividad es sin lugar a dudas la firma teórica de Butler, quien la define sucintamente como «(...) el poder reiterativo del discurso para producir los fenómenos que regula e impone» (Butler, 2002: 19). Con este concepto procura dar cuenta del proceso siempre inacabado por el cual se conforman tanto el género y la identidad -ejes de su primer trabajo, Gender trouble - como la materialidad del cuerpo y el sexo- noción central del segundo, Bodies that matter ${ }^{2}$.

Una vía que resulta fructífera para ahondar en la especificidad de la propuesta de Butler, y sentar las bases para un análisis crítico, consiste en trazar la genealogía del concepto de performatividad. Según sostiene B. Saez Tajafuerce (Cf. 2013) esta genealogía es doble. De un lado, remite a la teoría de los actos de habla, de J.L. Austin y J.R. Searle, que cabe ubicar como heredera de la concepción del lenguaje del segundo Wittgenstein, quien pone énfasis en la condición de praxis del lenguaje. Pero el concepto de Butler se diferencia del lingüístico por estar sujeto a otro régimen temporal. En esa distinción radica la segunda vertiente genealógica, que remite a la categoría de repetición, tal como fuera postulada por S. Kierkegaard ${ }^{3}$ y recuperada por J. Derrida ${ }^{4}$ mediante la noción de «iterabilidad», que Butler suscribe explícitamente.

Suscribirse a la posición derrideana acarrea dos consecuencias de peso para la teoría de Butler. En primer término, lo performativo ya no supone un acto que crea de una vez una nueva realidad (como en el clásico ejemplo lingüístico «Los declaro marido y mujer») sino que sólo logra hacerlo por un proceso de reiteración, por sedimentación. Pero además, y de modo más fundamental, el décalage entre una apelación a la cita y la /s que le sigue/n abre el margen que permitiría introducir variaciones. Y en lo tocante a la conformación del género, que es lo que interesa de entrada a Butler, tales variaciones ocasiones pueden subvertir la «norma heterosexista» volviéndola contra sí misma.

Para entender con precisión la noción de «norma heterosexista» es necesario dar un paso más allá de la genealogía, e introducir lo que cabe denominar como los ejes estratégicos de la empresa butleriana. Ello requiere considerar la apuesta política de su proyecto, que pretende denunciar y poner en cuestión dicha norma heterosexista, que presidiría el proceso

2 Conviene mencionar estos trabajos en su idioma original, porque en ambos casos se pierden en la traducción matices y sentidos relevantes. Sin embargo, para la citas utilizo las traducciones al castellano, no sin cotejarlas con las del idioma original cuando lo estimo necesario.

3 La repetición es una categoría central en el pensamiento de Kierkegaard, que en primer lugar se diferencia de la reminiscencia platónica, y que además le permite hacer frente a la mediación hegeliana (lo cual también explica su incidencia en el pensamiento contemporáneo post-metafísico). El filósofo danés elabora el concepto en una serie de textos entre 1843 y 1844, entre ellos el que se titula La repetición, atribuido a Constantin Constantius (en castellano: Alianza Editorial, 2009). El aspecto central del concepto según Kierkegaard, es que para que haya repetición algo tiene que cambiar entre la primera y la segunda vez, debe haber diferencia.

4 El filósofo francés ubica la iterabilidad como la estructura fundamental de la escritura y del lenguaje descrita como el décalage irreductible entre intención (o querer-decir) y sentido. En consecuencia, la iterabilidad introduce e implica la différance, es decir, el desplazamiento incesante e indeterminado de la significación, que tiene lugar por la ausencia de todo referente, lo cual no permite postular conceptos en sentido pleno, sino tan sólo reiteradas apelaciones a la cita, que nunca alcanzan a fijar el sentido Cf. Derrida, J. :«Firma, acontecimiento, contexto», en Márgenes de la filosofía. Madrid, Cátedra, 2004. Este volumen recoge el debate entre Derrida y J.R. Searle. 
de constitución de los cuerpos en tanto géneros. Así, ella misma describe su trabajo como «(...) una genealogía crítica de la naturalización del sexo y los cuerpos en general» (Butler, 2007, 286). Puesto que su cruzada política apunta a revelar cómo es que la homosexualidad, el lesbianismo, la intersexualidad y la transexualidad son construidas como identidades sexuales y/o cuerpos abyectos, lo desarrollado por M. Foucault acerca del dispositivo de sexualidad (Cf. Foucault, 2008) resulta un axioma teórico y estratégico fundamental. Butler adhiere a la idea foucaultiana según la cual el poder no sólo regula, reprime y disciplina, sino que es generativo, es decir, capaz de crear y reproducir las condiciones en las que opera (Cf. Butler, 2002). Radicalizando esta posición, ella sostiene que el cuerpo y el género sólo llegan a ser en tanto producidos por determinados dispositivos discursivos de poder y saber. Entonces, aunando a Foucault con Derrida, entiende la constitución de los cuerpos en tanto géneros como una estructura iterativa, que consiste en la apelación a la cita de una norma coercitiva heterosexista, norma que sólo existe fantasmáticamente por la reiterada citación de los discursos del poder, que arroja a la abyección los cuerpos que no se ajustan a ella.

De esta alianza Derrida-Foucault -y de la influencia del feminismo francés ${ }^{5}-$ deriva el segundo eje estratégico de Butler, y es que ella hereda por partida doble una actitud de desconfianza y una posición crítica respecto del psicoanálisis. El primero lo había acusado de falogocentrista, el segundo acabó por catalogarlo en la lista de las técnicas al servicio del biopoder, ubicándolo como parte fundamental del dispositivo de sexualidad ${ }^{6}$. Butler suscribe ambas críticas y además equipara la norma heterosexista dominante con el orden simbólico de Lacan, quien a su vez lo heredaría de la teoría del parentesco de Levi-Strauss. Incluso más, la teórica norteamericana somete las tres categorías de Lacan-simbólico, imaginario y real7 - a una remodelación que tiende a desdibujarlas. Destaquemos aquí el uso que hace de «lo simbólico», definido como «registro del ideal regulatorio» (Butler, 2002: 41). Para dar con esta definición, Butler somete la categoría lacaniana a una doble operación: de un lado transcribe la ley paterna y las relaciones de parentesco estructuralistas como instancias del

5 Son especialmente relevantes para Butler los trabajos de Luce Irigaray, Monique Wittig, Julia Kristeva.

6 De hecho, Foucault afirma que «la historia del dispositivo de sexualidad, tal como se desarrolló desde la edad clásica, puede valer como arqueología del psicoanálisis» (Cf. Foucault, M: Historia de la sexualidad I. «La voluntad de saber». Madrid, Siglo XXI, 1989. p. 158). En contra de esta acusación, Jean Allouch -psicoanalista contemporáneo, discípulo de Lacan- en El psicoanálisis ¿es un ejercicio espiritual? Respuesta a Michel Foucault (Buenos Aires, El Cuenco de Plata, 2007) reclama para el psicoanálisis otra genealogía, la de las técnicas espirituales, en base a lo desarrollado por el propio Foucault en Hermenéutica del sujeto (título del curso dictado en 1982. Publicado en castellano en Madrid, Ediciones de la Piqueta, 1994).

7 Estos registros elaborados por Lacan desde el inicio de su enseñanza constituyen tres categorías fundamentales de su aparato teórico, sujetas a variación a los largo de su obra, y por ende, sumamente complejas. A los fines de este trabajo, sólo cabe distinguirlas sucintamente poniendo de manifiesto el amplio espectro teórico que cada una de ellas abre. Lo imaginario remite a la teorización lacaniana conocida como «estadio del espejo», y se refiere a la incidencia de la imagen, particularmente en la conformación del yo y del cuerpo, que tiene lugar por la vía de la identificación con una Gestalt, es decir, una imagen de ilusoria completitud y su reverso, la imago del cuerpo fragmentado. Lo simbólico se refiere en primer lugar a la estructura del lenguaje que Lacan describió en su teoría del significante y su concepción del sujeto del inconsciente. En segundo término, la noción incluye una reelaboración de las leyes del parentesco estructuralistas, conjugadas con las elaboraciones freudianas acerca de la ley y el padre. Lo real se define ante todo como aquello que escapa a las posibilidades representativas de lo imaginario y lo simbólico. Se distingue de la realidad, y se define como «lo que vuelve siempre al mismo lugar» y más tarde como «lo que no cesa de no escribirse», es decir, lo que insiste como obstáculo, y es aquello que está en el núcleo del síntoma, emparentado directamente con el trauma y la angustia. 
poder en sentido foucaultiano, denominándolas como «lo simbólico». Del otro, ella suscribe -aunque sin mencionarlo- otros postulados teorizados por Lacan en los '50, a saber, la anterioridad lógica del Otro, el poder generativo del lenguaje y la materialidad del significante, que también forman parte de lo que él elaboró como «lo simbólico». Estos postulados son incorporados por la teórica queer y quedan subsumidos bajo su concepto de performatividad.

Este tratamiento de la categoría de lo simbólico sirve como paradigma de lo que aquí procuro destacar, a saber, que la actitud estratégica de Butler respecto del psicoanálisis -al igual que la de sus precursores, por lo demás, aunque ella va más lejos- no es lineal, sino ambivalente. En su opinión, «[e]l valor del psicoanálisis debe buscarse, obviamente, en una consideración acerca de cómo la identificación y los fracasos de ésta son cruciales para pensar la hegemonía» (Butler, 2000: 155). Por lo tanto, se constata que en la elaboración de su propuesta, el psicoanálisis tiene un lugar de peso estratégico, pero también teórico, ya que su posición respecto de él oscila entre la importación conceptual y la identificación del/con el adversario frente al cual construir el propio argumento. Veremos en lo que sigue que Butler recoge algunos conceptos del corpus psicoanalítico a la vez que rechaza otros, dando lugar a un debate abierto entre ambas teorías, en particular en cuanto al modo de concebir el cuerpo.

\section{El cuerpo como texto y la parodia en la primera formulación de la performatividad}

La tesis central de Gender Trouble, que «(...) el género es una imitación sin origen» (Butler, 2007: 269), se apoya en la lectura del trabajo de Joan Rivière titilado La femineidad como máscara (1929). Por esta vía se introduce una cierta noción de auto-fabricación del género, y, por ende, la posibilidad de transformación a la que estaría abierto. En efecto, en el célebre final de su primer libro, Butler propone la noción de «parodia» como mecanismo de resistencia y subversión política, con la Drag Queen como paradigma. Así, «[1]as categorías paródicas [bolleras, maricas, travestidos, etc.] sirven para desnaturalizar el sexo en sí» (Butler, 2007: 243). Se trata de ejemplos de lo que ella denomina «catacresis», a saber, el uso indebido o inapropiado de un término que logra subvertir la norma que lo regula (como el uso reivindicativo del término $« q u e e r{ }^{8}$ ). De este modo, la performativividad y la performance -en sentido artístico- resultan estrechamente ligadas como modos de revelar las múltiples construcciones posibles del género y la identidad, considerando al género como «un estilo corporal» (Ibídem: 271), una «reiteración estilizada de actos» (Ibídem: 275).

Con el objetivo de recusar toda idea de un cuerpo o instancia previa a la productividad discursiva Butler acentúa los «estilos corporales», poniendo de relieve la profusión de imágenes y rasgos mediante los cuales los cuerpos son significados y significan configurándose a sí mismos y a la identidad sexual mediante este proceso. En sus palabras:

Si la identidad se afirma por medio de un procedimiento de significación, si ya está significada y aún así sigue significando mientras se mueve dentro de distintos discursos entretejidos, entonces la capacidad de acción no puede contestarse apelando a un «yo» que exista antes de la significación (Butler, GD: 279).

8 Un análisis crítico del origen, usos e implicancias políticas que ha adquirido el término es efectuado por la propia Butler en Cuerpos que importan (2002 [1993]), en el capítulo titulado «Acerca del término 'queer'». 
Destaquemos algunas cuestiones importantes que se desprenden de esta cita. Lo fundamental es que si los cuerpos sólo son en tanto significados, y significan como identidades sexuales o géneros, entonces se enmarcan en el régimen textual, en el sentido de que no tienen más consistencia que las significaciones producidas por el discurso, y sin admitir la idea de «página en blanco» previa a la escritura. Por lo tanto, la superficie misma del cuerpo son esos significados, y en virtud de la iterabilidad derrideana que los crea y modifica cada vez que se reitera el gesto, el cuerpo es un texto que nunca logra completarse. Es decir, que el cuerpo es un texto siempre incompleto, pero texto al fin. De hecho, lo inacabado del proceso que lo condena a repetirse separa su teoría de un constructivismo simple, como el de Simone de Beauvoir.

Por otra parte, destacando otro aspecto relevante de la cita anterior, el margen de maniobra que los cuerpos tienen para resistir la norma dominante viene dado por el antagonismo entre los diversos discursos que regulan el tejido social, en tanto conjunto de significados complejos y convergentes cuyos efectos son vectores de poder, y de cuya pugna resultan los cuerpos y géneros que los discursos regulan. Y para dar cuenta del mecanismo por el cual los géneros se conforman en el marco de dicho antagonismo, Butler echa mano de la teoría de la identificación de Freud -según su lectura de «Duelo y Melancolía» (1917) ${ }^{9}$ - que explica el modo en que se adquieren determinados rasgos del objeto amado y perdido para conformar al yo ${ }^{10}$, identificación mediante. Lo que ella propone es que la identificación que conforma el género responde a una estructura melancólica: la identificación ${ }^{11}$ tiene lugar tras el rechazo del objeto homosexual que nunca es admitido ni llorado como tal, puesto que la prohibición del incesto presupone la prohibición de la homosexualidad, según sostiene Butler.

Al mismo tiempo, ella pretende dotar a los cuerpos de «capacidad de acción», es decir de agencia ${ }^{12}$, poniendo el énfasis en «las acciones corporales». Esto implica que los cuerpos se configuran en función de la norma pero también son capaces de resistirla, mediante desplazamientos paródicos, aunque sin apelar a un núcleo interior y anterior (llámese yo, cogito o como sea), sino tan sólo por efecto de la iteración de las acciones corporales, que logran desviar la norma haciendo diferencia entre una y otra repetición. De este modo procura recusar el dualismo cartesiano y la trascendencia del yo ${ }^{13}$.

9 Cf. Capítulo 2 de El género en disputa y sobre todo Mecanismos psíquicos del poder (ambos consignados en la bibliografía general).

10 Cabe señalar que al poner el énfasis en las identificaciones secundarias descritas por Freud para explicar la conformación de género, su lectura está más cerca de explicar la formación del yo que de una teoría del sujeto como efecto del significante como la que propone Lacan.

11 Para una crítica exhaustiva de la teoría butleriana de la identificación melancólica del género, cf. Cf. Žižek, S. (1998) «From 'Passionate Attachments' to Dis-idnetification». Umbr(a), Identity /Identification \# 1, pp. 3-18. Y también, del mismo autor: «(Des)apegos apasionados, o Judith Butler como lectora de Freud» en El espinoso sujeto. Buenos Aires: Paidós, 2001.

12 Este término tomado del inglés «agency» remite a la capacidad de acción de un «agente.» Su traducción al castellano resulta un tanto forzada, pero así se ha establecido en la bibliografía especializada, aunque más recientemente se ha optado por traducir «agentividad».

13 Desde esta perspectiva Butler critica el construccionismo de Beauvoir afirmando que hay allí un yo que «hace» su género y que «[e]se cogito nunca es plenamente del mundo cultural que negocia, independientemente de lo pequeña que sea la distancia ontológica que aleja a ese sujeto de sus predicados culturales» (Butler, 2007, 279). 
Pese a los esfuerzos de Butler por teorizar la estructura del género en relación con los mecanismos discursivos en pugna, el juego de las identificaciones y la agentividad del cuerpo, la noción de parodia pasó rápidamente a primer plano, dada su fuerte pregnancia. Como resultado, su teoría ha sido leída en clave constructivista y abrazada por quienes abogan por una concepción (exclusivamente) culturalista y por ende maleable del género. Como la misma Butler describió tras el boom de su primer libro, se leyó su trabajo como si ella hubiera sostenido que «(...) uno se despertaba cada mañana, examinaba el guardarropas o algún espacio más amplio en busca del género que quería elegir y se lo asignaba durante el día para volver a colocarlo en su lugar por la noche» (Butler, 2002: 12). Así, el deslizamiento hacia el género performativo (en vez de la estructura performativa del género) dio lugar a una extensa serie de apropiaciones apresuradas que han suscitado o se han fundado en la ilusión de una total plasticidad de aquel y en la capacidad voluntaria de modificarlo.

Las críticas no se hicieron esperar. A continuación enumeraré escuetamente -sin poder detenerme a analizarlas en profundidad-, las formuladas por dos autoras que defienden la teoría lacaniana contra el auge de las teorías de género.

J. Copjec - una de las críticas más corrosivas del trabajo de Butler- apunta de lleno contra la concepción del cuerpo como textualidad o significación paródica, cuando afirma que en definitiva se trata de «cuerpos de papel, sin ningún verdor» (Copjec, 2013: 62). Copjec $^{14}$ cataloga la posición de Butler como historicista, y le dirige tres objeciones: una objeción filosófica, de raigambre kantiana, según la cual, de modo ilegítimo, Butler deduce la inestabilidad de la Cosa en sí, a saber, el sexo, a partir de la inestabilidad de la significación, reduciendo el problema ontológico del sexo a la multiplicidad de géneros; una objeción ética, puesto que si se hace coincidir íntegramente al sujeto con el significante que lo conforma -y al cuerpo con el texto- en vez de ubicarlo como su falla u obstáculo, se lo hace totalmente permeable al control (por el contrario, el sujeto debe ubicarse como límite que habita al significante, señala Copjec, siguiendo a Lacan). Finalmente, una objeción psicoanalítica, que equipara la empresa butleriana con el proyecto de Carl Jung, por centrarse en el juego cultural de las significaciones para dar cuenta del sexo, dejando de lado el obstáculo fundamental, el cortocircuito del sentido que el sexo supone. El estatuto ontológico del sexo no es la significación y sus variaciones, sino que es del orden de lo real en sentido lacaniano, es decir, aquello que escapa a lo simbólico como obstáculo en el campo del sentido. Razón por la cual, concluye, además de voluntarista -ya que no tiene en cuenta el obstáculo- «(...) en todo cuanto dice [Butler] del sexo, elimina el sexo mismo» (Copjec, 2006: 33). Y por ende, añade, «género» resulta una categoría neutralizada, incluso «esterilizada» ${ }^{15}$.

14 Las tres críticas que aquí enumero son el núcleo del artículo «El sexo y la eutanasia de la razón», publicado en castellano en un volumen homónimo (Buenos Aires, Paidós, 2006). En inglés, el artículo está contenido en Read my desire: Lacan against the historicists. (Cambridge, MIT Press, 1996)

15 Este argumento y sus consecuencias son analizados en dos textos: «Encore. Un esfuerzo más por defender la diferencia sexual» en Ser-para-el-sexo. Diálogo entre filosofía y psicoanálisis (Barcelona, Ediciones S\&P, 2013); El compacto sexual (México, Paradiso Editores y 17, Instituto de Estudios Críticos, 2011). 
En consonancia con esta posición, A. Zupančič -en un detallado análisis de la relación entre diferencia sexual y ontología - afirma que la «[1]a performatividad es por tanto una clase de ontología de lo discursivo, responsable tanto del logos como del ser de las cosas» (Zupančič, 2013: 30). Y la objeción que ella le dirige se condensa en el siguiente párrafo:

Si la diferencia sexual es considerada en términos de género, se la hace - al menos en principio - compatible con los mecanismos de su ontologización. Puede que se digan «entidades puramente simbólicas», pero en cuanto tales no son pensadas como inherentemente problemáticas (Zupančič , 2013: 41).

Este argumento se articula con otra idea de Copjec, quien afirma que la teoría del género es nominalista porque reemplaza la teoría del sujeto dividido del psicoanálisis por una multiplicidad de Unos individuales sin otra unidad que la numérica, al mismo tiempo que elimina el obstáculo ontológico que supone el sexo y descarta el problema de la diferencia sexual.

A estas objeciones procura responder Butler en Cuerpos que importan, reformulando su teoría de la performatividad, según se expondrá en el próximo apartado.

\section{Materia y cuerpos abyectos en la segunda formulación de la performatividad}

Para desmarcarse de la posición de monismo lingüístico y constructivismo ${ }^{16}$ voluntarista ${ }^{17}$ que algunos críticos le imputan, Butler introduce una nueva noción que da título a su segundo libro, Bodies that matter: la materialidad del cuerpo que «se presenta en géneros» (Butler, 2002:11). Podría decirse que en respuesta a la acusación de hacer del cuerpo un cuerpo-texto «sin verdor», Butler se propone dotar a los cuerpos de otra textura que no sea ni meramente imaginaria y paródica, ni exclusivamente textual. Para ello debe articular la materialidad con su concepto de performatividad, reformulándolo. Propone entonces una noción de cuerpo como frontera entre materia y lenguaje, y la combina con otra noción, la de cuerpo abyecto. Consideraré a continuación cómo elabora y articula estas nociones de cuerpo, siempre procurando visibilizar la tensión abierta con el psicoanálisis.

Butler propone «la noción de materia no como sitio o superficie sino como un proceso de materialización que se estabiliza a través del tiempo para producir el efecto de frontera, de permanencia y de superficie que llamamos materia» (Butler, 2002: 28). Lo que quisiera poner en evidencia es que la elaboración de esta noción se funda en una importación conceptual del corpus freudiano, que si bien no está explicitada ni ha sido comentada, no

16 Ella analiza los ejes de este debate, y describe la versión constructivista que hace del género la construcción social del sexo, entendido como categoría natural y pre-existente. Rechazando esta versión, sostiene que toda idea de sexo como anterior al discurso es ya una idea construida en sí misma. Luego considera el «constructivismo radical», para el cual todo es siempre y únicamente lenguaje, un «monismo lingüístico» que padece de «somatofobia». Señala que esta posición tiene el inconveniente de mantener la estructura gramatical de la metafísica, haciendo del discurso o el poder un sujeto activo que lleva a cabo el acto de construcción, de una vez y para siempre. En sus palabras: «[n]o hay ningún poder que actúe, sólo hay una actuación reiterada que se hace poder en virtud de su persistencia e inestabilidad» (Butler, 2002: 28). Esa actuación es efectuada por los cuerpos, el énfasis está puesto en las acciones corporales, en desmedro de la noción de sujeto en sentido metafísico.

17 De la acusación de voluntarismo Butler se desmarca al afirmar que ella nunca ha postulado un sujeto que elije su género, sino que «su existencia está ya decidida por su género» (Butler, 2002: 13). 
por ello resulta menos relevante. Reconstruyamos el argumento de Butler: ella admite que hay una serie de materialidades que corresponden al cuerpo, y las nombra como «(...) la serie de significaciones que corresponden a la biología, la anatomía, la fisiología, la composición hormonal y química, la enfermedad, la edad, el peso, el metabolismo, la vida» (Butler, 2002: 108, las cursivas son mías). Aunque no pretende negar estas dimensiones del cuerpo, se trata en cualquier caso de significaciones, que además tienen una historia y una historicidad, agrega, y por tanto pueden y deben analizarse las «matrices interpretativas» que las condicionan. Pero con esta advertencia Butler no pretende sostener que la materia sea reductible al lenguaje ${ }^{18}$, por el contrario, debemos mantener la distinción entre ambos, sostiene con firmeza. Y a propósito de la morfología del cuerpo, afirma: «[1]os contornos corporales y la morfología no sólo están implicados en una tensión irreductible entre lo psíquico y lo material sino que son esa misma tensión» (Butler, 2002: 106). Aunque ella no lo menciona, la definición propuesta es muy cercana a la definición freudiana de la pulsión, concepto clave en la concepción psicoanalítica del cuerpo. En efecto, la pulsión fue definida por Freud como «un concepto fronterizo entre lo anímico y lo somático (...) como una medida de la exigencia de trabajo que es impuesto a lo anímico a consecuencia de su trabazón con lo corporal (Freud, 1992: 117, las cursivas son mías) ${ }^{19}$. Entonces, cabe afirmar que en su formulación de la morfología corporal, Butler permuta el término «somático» de la definición freudiana por «materia», mientras que a veces lo «psíquico» es reemplazado por «lenguaje». La omisión de esta referencia resulta sintomática, porque a renglón seguido la teórica norteamericana efectúa una operación de escamoteo teórico, y le adscribe a Freud una posición kantiana, según la cual la psique sería el agente somatizador o formativo de la morfología del cuerpo. Muy por el contrario, Freud ${ }^{20}$ recusa explícitamente las categorías a priori kantianas, y sostiene en cambio que la psique es en sí misma extensa y corpórea. Negando esta aportación fundamental, Butler se apropia de la posición freudiana y postula que el cuerpo se configura como «tensión irreductible» entre materia y lenguaje. Según Butler, la materia es:

(...) No la pizarra en blanco sino, antes bien, la demanda constitutiva que moviliza la acción psíquica desde el comienzo, que es esa movilización misma, y en su forma corporal transmutada y proyectada continúa siendo psique (Butler, 2002: 109).

18 Aquí se produce un deslizamiento que podría pasar inadvertido: el argumento ya no se refiere al discurso, como dispositivo de poder, sino al lenguaje. Merece sin duda señalarse que no queda claro si la teórica queer distingue entre estos dos términos o los usa de modo indistinto. Mientras su concepción del lenguaje remite a la de Searle y Austin combinada con la iterabilidad de Derrida (cf. Butler, J: Lenguaje, poder e identidad: Madrid, Síntesis, 2004), en cambio la noción de discurso es claramente tomada de Foucault, que refuerza el sentido de praxis y su articulación con los regímenes del poder.

19 Una definición muy similar a esta, tomada de «Pulsiones y destinos de pulsión» (1915) op. se encuentra ya en «Tres ensayos de teoría sexual» (1905). Ambos textos incluidos en Obras completas (Buenos Aires, Amorrortu, 1992), volumen XIV y VII respectivamente.

20 En una nota del 22 de agosto de 1938, Freud afirma: «Psique es extensa. Nada sabe de eso. La espacialidad acaso sea la proyección del carácter extenso del aparato psíquico. Ninguna otra derivación es verosímil. En lugar de las condiciones a priori de Kant nuestro aparato psíquico» (Freud,1992, 302). Cf. «Conclusiones, ideas, problemas» (1937-1938) en Freud, S. op.cit vol. XXIII. 
En esta cita puede verse con claridad la importación de la estructura fronteriza del concepto freudiano de pulsión y la idea de una presencia activa de la corporeidad en la psique, ya concebida por el inventor del psicoanálisis en la noción de «vida psíquica» ${ }^{21}$. Los cuerpos, concluye Butler, son «materia de significación», pero ello no significa que el cuerpo sea sencillamente materia lingüística, aunque tampoco que su actividad no influya en la significación. Al mismo tiempo, no puede haber ninguna referencia a una materialidad pura, puesto que todo esfuerzo por referirse a ella se realiza por un proceso significante. Sin embargo, insiste, no puede reducirse la materialidad a una identidad con el lenguaje. Entonces, de Gender Trouble a Bodies that matter, hay un desplazamiento de una definición de lo corpóreo fundada en la imagen del cuerpo-texto y el género paródico, a otra que se apoya en la figura del cuerpo concebido como frontera, lo cual se hace evidente cuando afirma que «(...) un movimiento fronterizo en sí mismo parece ser imprescindible para establecer lo que los cuerpos 'son'» (Ibídem: 11, las cursivas son mías), y esa frontera es la que media entre la materia y el lenguaje.

No obstante, resulta fundamental destacar que la analogía con el concepto de Freud es ante todo formal, porque el campo semántico y conceptual entre ambas teorías difiere notablemente, con el cuerpo materializado como género de un lado, y el cuerpo pulsional del otro. Justamente en torno al estatuto del cuerpo puede trazarse la línea que divide ambas teorías, aunque pueden hallarse algunos puntos de intersección. Por ejemplo, y en lo que atañe al foco de este trabajo, Lacan y Butler coinciden en que no hay cuerpo antes de la puesta en macha de un determinando discurso. Pero ella reduce lo que hay después de la operatividad del discurso a los cuerpos materializados como géneros, según el antagonismo de las significaciones en pugna. En cambio, Lacan postula que en todo discurso, además de la producción de significaciones antagónicas, está en juego la producción y regulación del goce (pulsional, sexual), e incluso un margen de goce que escapa a dicha regulación por más que sea efecto del discurso. Por lo tanto, el concepto de goce representa su aportación capital, ya que permite situar la especificidad de la condición fronteriza del cuerpo, como «sustancia gozante» (Lacan, 2006b,) no sin el significante. Sin embargo, este concepto no es tenido en cuenta por Butler. Su argumento por momentos ronda lo tautológico: la materialidad de los cuerpos es efecto de la reiteración de normas discursivas en tanto significaciones dominantes, y la materialización de la que es capaz el lenguaje es demostrada por esos mismos cuerpos. Esta remisión circular deja su teoría en el límite del monismo discursivo que sus críticos le imputan. Quizás hay que creerle cuando confiesa: «(...) no soy una buena materialista. Cada vez que intento escribir sobre el cuerpo termino escribiendo sobre el lenguaje» (Butler, 2006: 280).

La otra noción de cuerpo relevante en la segunda formulación de la teoría de la performatividad es la de cuerpo abyecto, que Butler construye conjugando su lectura del trabajo de Julia Kristeva 22 con una referencia negativa y explícita a la categoría de lo real elaborada por

21 Cf. Assoun, P.-L. (1997): Leçons psychanalytiques sur Corps et Symptôme. Tome «Clinique du corps», Tome 2 «Corps e Inconscient». Paris: Anthropos.

22 Esta lectura tiene lugar en el capítulo 3 de Gender Trouble, en el que critica duramente a Kristeva por su concepto de «lo semiótico», adherido a lo maternal. Sin embargo recupera la noción de lo abyecto siguiendo la pista de la siguiente afirmación de Kristeva: «No es por lo tanto la ausencia de limpieza o de salud lo que lo vuelve abyecto, sino aquello que perturba una identidad, un sistema, un orden. Aquello que no respeta los 
Lacan. Vale la pena reconstruir el argumento. La autora sostiene que «[1]a fuerza normativa de la performatividad -su poder de establecer lo que ha de considerarse 'ser'- se ejerce no sólo mediante la reiteración, también se aplica mediante la exclusión» (Butler, 2002: 268). Aplicando esta idea al sexo, plantea que el imperativo heterosexista pone en marcha mecanismos discursivos que permiten ciertas identificaciones sexuadas o géneros, mientras que excluyen y repudian otras, «[y] en el caso de los cuerpos, tales exclusiones amenazan la significación constituyendo sus márgenes abyectos o aquello que está estrictamente forcluido: lo invisible, lo inenarrable, lo traumático» (Butler, CI: 268). Así, determinados cuerpos se materializan como abyectos y son arrojados fuera de lo humano constituyendo lo exterior respecto de los términos de la sociabilidad, de modo tal que lo humano se produce por encima y en contra de lo inhumano. Pero además, este exterior abyecto es interior al sujeto como su propio repudio fundacional, puesto que «[1]a formación de un sujeto exige una identificación con el fantasma normativo del 'sexo' y esta identificación se da a través de un repudio que produce un campo de abyección, un repudio sin el cual el sujeto no puede emerger» (Butler, 2002: 20), lo cual se articula con lo que había desarrollado sobre el rechazo melancólico del objeto homosexual. No obstante, ni en un nivel ni en otro, se trata de un «exterior absoluto» o externalidad ontológica que se oponga al campo abierto por el discurso. Por el contrario, la exclusión y la materialización de los cuerpos abyectos también tienen lugar mediante mecanismos discursivos, es decir, que hay un ámbito «exterior», pero sólo en tanto discursivamente construido como tal. Si Butler dedica un capítulo a rechazar de manera tajante la categoría de lo real ${ }^{23}$ propuesta por Lacan es porque, en su opinión ${ }^{24}$, supone el riesgo de reintroducir lo que ella combate, a saber la idea de algo «anterior» o independiente del efecto generador del lenguaje y los dispositivos del poder. Lo que ella no admite es que la exclusión se formule sin un texto o significación social específica, porque teme que se reintroduzca una categoría trascendental y/o a-histórica. Hay sobre este punto un claro malentendido por parte de Butler, ya que lo real lacaniano no es el nóumeno ni ninguna categoría ontológica. En palabras del propio Lacan: «(...) lo real, justamente, es lo que anda mal, lo que se pone en cruz ante la carretera, más aún, lo que no deja de repetirse para estorbar ese andar» (Lacan, 2006c: 81). Butler se empeña en describir un exterior constitutivo que es producto de los mecanismos discursivos. Lo real de Lacan es la imposibilidad estructural con que se topa todo mecanismos discursivo ${ }^{25}$. En cambio, en la

límites, los lugares las reglas. La complicidad, lo ambiguo, lo mixto» (Cf. Kristeva, J. Poderes de la perversión. Ensayo sobre Louis-Ferdinand Céline, Buenos Aires: Siglo XXI, 1989 pp.11) Extrayendo esta idea de resistencia ante un orden establecido para situarla en un contexto de reivindicación teórica y política queer, Butler le da a lo abyecto un nuevo estatuto.

23 No pudo asumir aquí las densas implicaciones del debate en torno a lo real. Al respecto, conviene remitirse al acalorado debate a tres voces que sostiene junto a Žižek y Ernesto Laclau, en Contingencia,hegemonía, universalidad (Buenos Aires, Fondo de Cultura económica, 2004). Butler critica el uso de dicha noción, mientras Žižek y Laclau, aunque por senderos diversos, se empeñan en defenderla y mostrar su operatividad para el análisis del campo político.

24 A decir verdad, sobre este punto ella no discute con Lacan, cuyos desarrollos al respecto omite casi por completo, sino con lo teorizado por S. Žižek, cuya lectura, no siempre coincide estrictamente con la de Lacan. Coincido con la posición de J. Sáez quien señala -en Teoría queer y psicoanálisis- que en el texto de Butler (capítulo 7 de Bodies that matter, titulado «Discutir con lo real») las citas de Lacan son escasas, incluso que son erróneas, y que su lectura de lo postulado por el teórico esloveno da lugar a graves malentendidos.

25 En términos del debate de la diferencia sexual, que es un punto de litigio fundamental entre estas teorías, la cuestión se plantearía así según la perspectiva lacaniana: toda formulación de la diferencia sexual en términos 
teoría de Butler lo «excluido» tiene siempre un contenido social, con una imagen específica: los cuerpos abyectos. Y, una vez más, puesto que hay múltiples discursos sociales en pugna que luchan por imponer determinada sedimentación performativa, el límite puede ser subvertido mediante la catacresis, la desidentificación y la renegociación de la frontera de modo tal que los cuerpos arrojados a la abyección finalmente «importen» (matter) y puedan tener vidas dignas de ser vividas. Tal es la apuesta política de Butler, en la que los cuerpos abyectos pueden producir efectos de subversión, porque son la materialización de la noción de frontera con la que la teórica queer procura resolver los problemas de la figura del cuerpo-texto paródico de su primer trabajo. Los cuerpos abyectos encarnan la frontera, y son al mismo tiempo capaces de renegociarla, puesto que acorde con su posición de partida, están dotados de agentividad.

Entonces, para cerrar este apartado, conviene recapitular y sintetizar los resultados del análisis de la empresa butleriana en cuanto al modo en que concibe el cuerpo: ella comienza por enfatizar una noción de cuerpo-texto capaz de variación paródica, para luego subrayar el efecto generativo y materializador del lenguaje, formulando la noción de cuerpo como «frontera» entre el lenguaje y una materialidad que sólo admite ser situada según determinadas significaciones históricas, abiertas a la pugna por la hegemonía. De allí que la apuesta política pase por los cuerpos abyectos, es decir, aquellos que encarnan la frontera entre lo que la norma legitima y lo que expulsa fuera, y que por tanto son capaces de subvertirla y renegociarla.

\section{Crítica lacaniana de los cuerpos abyectos y la lógica identitaria}

Del mismo modo que Copjec y otros han criticado la noción de cuerpo que fundamenta la primera formulación de la teoría de la performatividad, se puede poner en cuestión la tesis de los cuerpos abyectos, echando mano precisamente de aquellos desarrollos que Butler deja de lado en su lectura de Lacan. Desde el ámbito psicoanalítico se ha señalado reiteradamente que la crítica butleriana al supuesto heterosexismo del psicoanálisis peca de anacronismo, puesto que se centra casi con exclusividad en el texto de Lacan titulado «La significación del falo» (1958), omitiendo toda mención a la reformulación del problema de la diferencia sexual que él elaboró a inicios de los años ' $70^{26}$, conocida como «fórmulas de la sexuación». Aunque no es posible dar cuenta en este contexto de la complejidad y el rigor de esta teoría, procuraré ofrecer unos lineamiento generales ${ }^{27}$, de modo de hacer inteligible los argumentos críticos. Lo original de este enfoque es que se trata de una aproximación lógica al problema de la diferencia sexual que hecha por tierra la acusación de binarismo, ya que las dos modalidades lógicas que distingue no son opuestas complementarias. De hecho, el punto de partida de esta teorización es lo real descubierto por la experiencia analítica, condensado

simbólicos está condenada al fracaso, la relación sexual no puede escribirse en lo simbólico y es justamente por ello que tiene lugar la lucha hegemónica por el significado de la diferencia sexual. Y ese fracaso no es del mismo orden que aquello que determinado régimen discursivo excluye, no es equivalente a lo excluido según tal o cual contenido social, sino que es la imposibilidad radical, real, de todo discurso, incluido el heterosexista, de suturar o resolver el problema de la diferencia sexual.

26 En verdad esta omisión no es casual, sino que es consecuente con el alegato en contra de la categoría lacaniana de lo real, que es justamente el registro privilegiado por Lacan a partir de los '70.

27 Para una introducción clara y precisa a esta teorización, cf. Cevasco, R: La discordancia de los sexos. Perspectivas psicoanalíticas para un debate actual (Barcelona, S\&P, 2010). 
en el célebre aforismo lacaniano «No hay relación/ proporción sexual» ${ }^{28}$. Esto quiere decir que no hay en la experiencia humana -afectada por la estructura del lenguaje- un programa predeterminado para la distribución de la posición sexuada, tampoco dos mitades que encastren entre sí en proporción alguna. Lo que hay son dos modalidades disimétricas respecto de una función lógica. Esta función, denominada función fálica, es una formalización de la castración entendida como la pérdida de goce que se produce en todo «parlêtre» (hablaser) por la incorporación del lenguaje. La posición sexuada y la modalidad de goce de cada quien dependerá del modo en que se subjetiva esa pérdida estructural. Habría entonces una manera «masculina» y otra «femenina» de articular la función, cada una con un impasse, puesto que se trata de dos modos de situarse ante la ausencia estructural de la relación sexual. Y entre esas posiciones no hay proporción binaria sino discordancia, disyunción, no-relación. De un lado, llamado «masculino», se ubican los sujetos (con independencia del sexo biológico y de la materialización de lo cuerpos como género) para quienes el goce es Todo fálico, es decir enteramente concernido por la función fálica. Ese Todo, afirma Lacan, se configura como un conjunto cerrado dejando fuera, como suposición lógica, «al menos uno» que no está concernido por la función. En cambio, para quienes se ubican del lado «femenino», el goce no está enteramente concernido por la función. Es decir que de este lado hay dos vectores de goce: hay el goce fálico, es decir, concernido por la función, pero además, existe la posibilidad de un goce otro que el fálico, más allá del falo, un goce no-todo fálico, suplementario. Y ese goce no-todo persiste como un margen de indeterminación, es decir que no es generalizable, no se presta a los mecanismos de la identificación. En consecuencia, $-\mathrm{y}$ esto es fundamental- no se puede formar un conjunto de quienes se ubican del lado femenino $^{29}$, por eso, decía Lacan, a las «mujeres» no queda más que tomarlas una por una. De allí el otro célebre aforismo: «La mujer no existe», lo cual quiere decir que no existe como categoría universal, no es posible cerrar el conjunto, formalizar un Todo.

Como señala R. Cevasco, lo interesante de las fórmulas de la sexuación es que resultan una herramienta crítica poderosa, ya que la formalización que ofrecen puede ampliarse a otros campos de lectura. De hecho, puede verificarse su incidencia política en el plano de las formaciones colectivas, ya que permiten distinguir: de un lado, los colectivos organizados según la lógica del «Todo», cuyos correlatos mortíferos de segregación son bien conocidos, puesto que se fundan en la exclusión de «al menos uno» para cerrar el conjunto (dicho en términos más coloquiales, siempre que se organiza un «nosotros» hay algún otro que queda fuera). Y del otro: «[1]a parte del «no todo» que no se resuelve en identificación alguna, abre la oportunidad de pensar en una lógica colectiva otra que la basada en una lógica identitaria» (Cevasco, 2013: 100).

Entonces, tomando apoyo en las fórmulas lacanianas, se puede afirmar que la lógica identitaria subyace a todo el planteo político de Butler. En efecto, aunque realiza la proeza teórica de reunir la problematización de los roles de género propiciados por la dominación

28 En francés, «il n'ya pas de rapport sexuel» evoca ambos sentidos. Este aforismo lacaniano se encuentra en múltiples escritos. En cuanto a las fórmulas de la sexuación, comienza a desarrollarlas en el seminario 19 , titulado au pire... (Paris, Seuil, 2011) y las acaba de formalizar en el seminario 20, Aun (Buenos Aires, Paidós, 2006).

29 Insistamos: cada sujeto puede posicionarse de un lado u otro de las fórmulas independientemente de su sexo anatómico y su género. De hecho, cuando se trata de dar ejemplos del goce no-todo fálico, Lacan recurre a la experiencia de los místicos, Santa Teresa de Jesús, pero también San Juan de la Cruz.. 
patriarcal y heterosexista sin caer en la afirmación de una identidad (femenina) en sentido fuerte, Butler conserva la operatividad política de la categoría de identidad, abriendo el margen de transformación por medio de la iteración performativa y la multiplicación de las identidades de género. Y la lógica identitaria encuentra su corolario en la teorización de los cuerpos abyectos, es decir, aquellos que constituyen el exterior constitutivo de la norma, que encarnarían lo excluido que permite sostener el Todo, o parafraseando su argumento, lo inhumano sobre lo que se erige lo humano.

Butler aboga entonces por un orden simbólico más «inclusivo», pero de este modo permanece entrampada en la lógica del Todo. El callejón sin salida en el que una reivindicación de esta índole desemboca es que la frontera -para retomar su metáfora- es móvil y por ende, como el horizonte, siempre se mueve un poco más allá. Así, lo excluido puede ir desde las expresiones más brutales del antisemitismo y el racismo, pasando por la homofobia para llegar a eso que Freud llamó, con gran sagacidad, «narcisismo de las pequeñas diferencias», es decir, el detalle nimio que sin embargo es capaz de desatar el odio más destructivo. Que el argumento de Butler se sostiene en esta lógica lo demuestra un episodio que ella misma protagonizó hace pocos años cuando rechazó el «Berlin Pride Civil Courage Prize» 2010 denunciando la complicidad racista y nacionalista del comité organizador ${ }^{30}$. Este episodio permite poner de manifiesto dos cuestiones: la primera, que los movimientos gay, lesbianos, trans y queer articulan su propia política identitaria, y por ende, sus propios mecanismos de segregación. La segunda que aún cuando estos movimientos han hecho mucho por los derechos civiles de tales colectivos - y en ningún caso se trata de negar el valor y la importancia de esa lucha política y mucho menos del terreno ganado- la frontera de la abyección se mueve adhiriendo a otros rasgos sobre los cuales sostener la exclusión, de modo que si ya no se trata del género, la cuestión se traslada al credo, la raza o la nacionalidad. Y este deslizamiento no encuentra punto de basta, puesto que siempre será posible extraer un rasgo sobre el cual sostener la segregación.

En consecuencia, desde la perspectiva del psicoanálisis lacaniano, y en palabras de J. Alemán: (...) el auténtico desmantelamiento del falocentrismo no es oponerle identidades que lo reinscriban y se multipliquen en géneros, sino hacer comparecer la lógica de no-todo. (Alemán, 2003). Esto significa que contra la política de la multiplicación de identidades, el psicoanálisis, con Lacan, ofrece el no-todo y su posible eficacia política, contra identitaria, abriendo una apuesta en la que diversos pensadores se han embarcado más o menos recientemente.

No parece ser el caso de Butler, quien, como ya he señalado, hace caso omiso de estas teorizaciones lacanianas. Sin embargo, la crítica antepuesta permite hacer inteligible el giro acaecido en la última producción teórica de Butler, en la que propone el concepto de vulnerabilidad como una nueva vía para situar la especificidad del cuerpo. En efecto, con este concepto ella procura dar con una condición universal de los cuerpos, e incluso más, ofrece cierta aproximación ontológica cuando afirma: «(...) la vulnerabilidad es el nombre atribuido a una cierta manera de apertura al mundo. En este sentido, la palabra no sólo designa una relación con dicho mundo, sino que afirma el carácter relacional de nuestra existencia» (Butler, 2014: 49).

30 Pueden encontrarse online múltiples artículos que hacen alusión a este episodio. He aquí el link de uno de ellos, escrito por una de las organizaciones a la que Butler cede su premio: http://nohomonationalism.blogspot.com. es/2010/06/judith-butler-refuses-berlin-pride.html 
¿Sería acaso posible conjugar de algún modo la eficacia contra identitaria del no-todo lacaniano con el universal ontológico y corpóreo elaborado por Butler? A primera vista la respuesta no resulta evidente, aunque sin dudas abre la ocasión para otra reflexión. En cualquier caso es una pregunta que vale la pena dejar abierta, de modo de no cancelar la tensión teórica que he recorrido en este artículo, y que a todas luces ha resultado fecunda.

\section{Referencias}

Alemán, J. (2003): «Lacan, Foucault: el debate sobre el construccionismo».Virtualia, en Revista digital de la Escuela de Orientación Lacaniana. Abril-Mayo 2003, año 2, $\mathrm{N}^{\mathrm{o}} 7$.

Butler, J. (2014): «Vida precaria, vulnerabilidad y ética», en Saez Tajefuerce, B. (Ed.): Cuerpo, memoria y representación. Barcelona: Icaria, 2014.

Butler, J. (2007 [1990]): El género en disputa. El feminismo y la subversión de la identidad. Barcelona: Paidós. Traducción de $\mathrm{M}^{\mathrm{a}} \mathrm{A}$. Muñoz.

Butler, J. (2002 [1993]) Cuerpos que importan. Sobre los límites materiales y discursivos del «sexo». Buenos Aires/Barcelona/México: Paidós. Traducción de A. Bixio.

Butler, J. (2006 [2004]): Deshacer el género. Barcelona: Paidós Ibérica. Traducción de P. Soley-Beltrán.

Butler, J. (2001 [1997]): Mecanismos psíquicos del poder. Teorías de la sujeción. Madrid: Ediciones Cátedra. Capítulo III y IV.

Butler, J., Laclau, E. \& Žižek, S. (2000): Contingencia, hegemonía, universalidad. Diálogos contemporáneos en la izquierda. Buenos Aires: Fondo de cultura económica.

Cevasco, R. (2010): La discordancia de los sexos. Perspectivas psicoanalíticas para un debate actual. Barcelona: Ediciones S\&P.

Copjec, J. (2013): Encore, Un esfuerzo más por defender la diferencia sexual, en Zupančič, A., Copejc, J. \& Cevasco, R.: Ser-para-el-sexo. Diálogo entre filosofía y psicoanálisis. Barcelona: Ediciones S\&P. Traducción de A. C. González.

Copjec, J. (2006): El sexo y la eutanasia de la razón. Ensayos sobre el amor y la diferencia. Buenos Aires: Paidós. Traducción de G. Ubaldini. Capítulo I.

Copjec, J. (2011): El compacto sexual. México: Paradiso Editores, 17 Instituto de Estudios Críticos. Capítulos I y IV.

Foucault, M. (2008): Historia de la sexualidad. Volumen I «La voluntad de saber». Buenos Aires: Siglo XXI. Traducción de U. Guiñazú.

Freud, S. (1992): «Pulsiones y destinos de pulsión» (1915) y «Conclusiones, ideas, problemas» (1937-1938), en Obras completas, vol. XIV. Buenos Aires: Amorrortu. Traducción de J. L. Etcheverry.

Lacan, J. (2006a): De nuestros antecedentes, en Escritos. Barcelona: RBA Coleccionables, versión y traducción cedida por Ediciones Siglo XXI. Traducción de T. Segovia, revisada por J. D Nasio. pp. 59-66.

Lacan, J. (2006b): El Seminario. Libro 20. Aun (1972-1973). Buenos Aires: Paidós. Traducción de D. Rabinovich, J. L. Delmont-Mauri y J. Sucre.

Lacan, J. (2006c): «La tercera», en Intervenciones y textos II. Buenos Aires: Manantial. Traducción J. Sucre, J. L. Delmont Mauri y D. Rabinovich.

Sáez, J. (2008): Teoría queer y psicoanálisis. Madrid: Editorial Síntesis. 
Saez Tajafuerce, B. (2013): «Leyendo a Rithée Cevasco leyendo a Lacan leyendo el cuerpo», en González, A. C. \& Saez Tajafuerce, B . (Eds.): Analizando el cuerpo la vigencia política del psicoanálisis. Barcelona: Ediciones S\&P, 103-113.

Zupančič, A. (2013): «Diferencia sexual y ontología» en Zupančič, A., Copejc, J. \& Cevasco, R.: Ser-para-el-sexo. Diálogo entre filosofía y psicoanálisis. Barcelona: Ediciones S\&P. Traducción de A. C. González. 